\title{
Increased albumin excretion in industrial workers due to shift work rather than to prolonged exposure to low concentrations of chlorinated hydrocarbons
}

\author{
P J Boogaard, M E J Caubo
}

\begin{abstract}
Objectives-It has been reported that groups of workers in petrochemical industries who have been exposed to low concentrations of chemicals for prolonged periods have an increased urinary albumin excretion compared with unexposed controls. This increase, however, seemed to be unrelated to the extent, duration, and type of exposure. The aim of the present study was to investigate the suggestion that the small increase in albumin excretion might be due to differences in physical workload between the exposed and control groups or to the fact that the exposed workers are shift workers whereas the controls are employed on day duty.

Methods-To elucidate the effect of shift work, again a series of renal and hepatic variables were studied in organochlorine workers but now with two different control groups. One control group comprised shift workers and the other only workers on day duty. The exposed and both control groups had roughly equal physical workloads, although one control group comprised shift workers and the other workers who work only during day time.
\end{abstract}

Results-There were no significant changes in the results of the liver tests between the exposed group and either of the control groups, nor between the two control groups. No significant differences for any renal test were found between the exposed workers and control shift workers, but albumin was significantly lower in the control day workers than in the exposed workers and control shift workers.

Conclusions-The results suggest that the previously reported small increase in albuminuria in industrial workers is due to alterations in circadian rhythms due to the shift work system rather than to prolonged exposure to low concentrations of potentially nephrotoxic chemicals.

(Occup Environ Med 1994;51:638-641)

Keywords: albuminuria, shift work, nephrotoxicity

Recently we evaluated the renal and hepatic effects of prolonged exposure to low concentrations of a number of chlorinated hydrocarbons (mainly allyl chloride, epichlorohydrin, 1,3-dichloropropene, and hexachlorocyclopentadiene) in a group of industrial workers. ${ }^{1}$ No clinically significant effects on kidney or liver were detected nor were biochemical alterations in liver functions found compared with a matched control group of office workers with no occupational exposure to halogenated hydrocarbons. Also, urinary alanine aminopeptidase, $\quad N$-acetyl- $\beta$-D-glucosaminidase, and retinol binding protein, which are biochemicals used to detect early defects in renal tubular function, did not differ between the exposed and the control group. Urinary albumin, however, was significantly higher in the exposed group. Viau et al have reported strikingly similar findings in a refinery population exposed to hydrocarbon solvents: no differences in $\beta_{2}$-microglobulin, retinol binding protein, or $N$-acetyl- $\beta$-D-glucosaminidase but a statistically significant rise, albeit within the normal range, in albumin excretion in refinery employees compared with a matched control group with clerical or administrative functions. ${ }^{2}$ Like these authors, we were unable to relate this small increase in albumin excretion to the duration of exposure. Urinary albumin, also, was not related to exposure to the different halogenated hydrocarbons. In this short report we present the results of a study in which we examined biochemical markers of kidney and liver damage in two different control groups of not occupationally exposed workers and in the same group of workers exposed to low concentrations of chlorinated hydrocarbons to find an explanation for their increased albumin excretion.

\section{Materials and methods}

POPULATION AND STUDY DESIGN

The exposed group comprised 94 men working in five shifts at the organochlorine plant. Of the 73 workers that attended the previous occupational health assessment, in which the rise in urinary albumin was detected, ${ }^{1} 64$ $(88 \%)$ were still employed at the plant and attended the present occupational health assessment. For this subset of 64 workers the present results were compared with the results obtained two years earlier.

In control group 1 were 60 men working in five shifts at the petroleum refinery. Control group 2 consisted of 50 men from the maintenance division employed on day duty. The workers from both control groups have no occupational exposure to halogenated hydrocarbons. The subjects of the exposed and control groups participated in voluntary periodic 
occupational health assessments held during the same period. Information was obtained by means of a self administered questionnaire on occupational history, demographic characteristics, and life style. All questionnaires were reviewed by the medical officers of the respective plants for accuracy and completeness. Subjects with a known history of non-occupational nephropathies or urinary tract diseases were excluded from the study as well as subjects with a systemic disease with possible renal or hepatic sequelae such as diabetes mellitus or thalassemia minor.

From all participants blood and urine samples were collected between 0800 and 1000 . The urinary enzymes alanine aminopeptidase and $N$-acetyl- $\beta$-D-glucosaminidase, the urinary proteins albumin and $\beta_{2}$-microglobulin, and serum creatinine were measured to evaluate effects on the kidney. Possible effects on the liver were studied by the determination of serum alanine aminotransferase, alkaline phosphatase, aspartate aminotransferase, total bilirubin, $\gamma$-glutamyltranspeptidase, and lactate dehydrogenase.

\section{ANALYTICAL METHODS}

Spot urine samples were collected in polythene containers. Specific gravity and $\mathrm{pH}$ were determined immediately after sampling. As $\beta_{2}$-microglobulin is degraded in the bladder at $\mathrm{pH}<5 \cdot 5,{ }^{3}$ workers who provided a urine sample with a lower $\mathrm{pH}$ were asked to collect a new sample, which, if necessary was adjusted to a pH of about 7 immediately after voiding. The urine samples were split into fractions and stored at $-20^{\circ} \mathrm{C}$ until analysis except the fractions for albumin determination, which were preserved by addition of sodium azide ( $15 \mu \mathrm{M}$ final concentration) and stored at $4^{\circ} \mathrm{C}$. The fractions for alanine aminopeptidase analysis were preserved with ethylene glycol ( $30 \%$ by volume) before freezing.

Alanine aminopeptidase was determined on a Cobas Mira autoanalyser according to the method of Mattenheimer et $a l^{4}$ at a temperature of $30^{\circ} \mathrm{C}$. As expected, this resulted in higher absolute values than reported in the previous study where alanine aminopeptidase was determined manually at a temperature of $25^{\circ} \mathrm{C}$. Albumin was determined by immunoturbidimetry (UniKit, Roche Diagnostics) on a Cobas Mira autoanalyser and $\beta_{2}$-microglobulin by radio immunoassay (Phadebas,

Table 1 Characteristics of the exposed and control groups

\begin{tabular}{|c|c|c|c|}
\hline & \multicolumn{2}{|c|}{ Shift workers } & \multirow{2}{*}{$\begin{array}{l}\text { Day workers } \\
\text { Control } 2\end{array}$} \\
\hline & Exposed & Control 1 & \\
\hline $\begin{array}{l}\text { No of volunteers } \\
\text { Mean age }(\mathrm{y}) \\
\text { Mean length }(\mathrm{cm}) \\
\text { Body mass index } \\
\text { No of smokers (\%) } \\
\text { Smoking habits (cigarettes/day) } \\
\text { No of alcohol users }(\%) \\
\text { Alcohol consumption (glasses/week) } \\
\text { No of regular exercisers (\%) } \\
\text { No of medication users }(\%)\end{array}$ & $\begin{array}{l}93 \\
38 \cdot 1 \\
179 \cdot 7 \\
25 \cdot 8 \\
36(39) \\
5 \cdot 4 \\
86(93) \\
12 \cdot 1 \\
47(50) \\
10(11)\end{array}$ & $\begin{array}{l}60 \\
38 \cdot 9 \\
182 \cdot 1 \\
25 \cdot 3 \\
19(32) \\
5 \cdot 0 \\
50(83) \\
8 \cdot 0 \\
31(52) \\
13^{\star}(22)\end{array}$ & $\begin{array}{l}50 \\
39 \cdot 7 \\
179 \cdot 3 \\
25 \cdot 4 \\
14(28) \\
3 \cdot 4 \\
45(50) \\
11 \cdot 6 \\
25(50) \\
3^{\star}(6)\end{array}$ \\
\hline
\end{tabular}

^Values with the same superscript differ significantly $(P<0.05)$.
Pharmacia Diagnostics). $\quad N$-acetyl- $\beta$-D glucosaminidase in urine and all liver enzymes, serum creatinine and bilirubin in serum were determined as previously described. ${ }^{1}$ All urine variables were normalised for urinary creatinine concentration, determined by alkaline picrate colorimetry (Jaffé method) on a Cobas Mira autoanalyser.

\section{STATISTICS}

Statistical analyses of the results of the exposed group and both control groups were performed with the mainframe version of the SAS statistical software package (version 6.06) with $P<0.05$ as level of significance as previously described. ${ }^{1}$ The present results of the 64 workers from the exposed group who also participated in the previous study cannot simply be compared with the results obtained in 1990 because they are not independent. Therefore, for each individual the change in time of each of the variables was calculated. It was tested whether these changes differed from zero (Student's $t$ test).

\section{Results}

POPULATIONS

Ninety four of the workers from the organochlorine plant attended the voluntary occupational health assessment (response rate $98 \%$ ). One man was excluded from the study as his urine sample was too dilute for reliable determination of the urinary variables. Sixty of the 80 refinery workers (response rate $75 \%$ ) and 50 of the 68 maintenance workers (response rate $74 \%$ ) attended the occupational health assessment.

Table 1 summarises the characteristics of the exposed and both control groups. The groups matched well for all variables except that the number of medication users in control group 1 was significantly higher $(P=$ $0.016)$ than in control group 2 and similar to the level in the exposed group. It seemed, however, that medication was not a significant confounder for any of the tests. Over the period from 1990 to 1992 , there were only minor changes with no statistical significance in the characteristics of the subset of 64 potentially exposed workers who attended the occupational health assessment in both years, with exception of course of the increase in age.

\section{BIOCHEMICAL TESTS}

There were no significant differences in the results of the liver tests between the exposed group and either of the control groups, nor between the two control groups. There were also no significant changes in the results of the liver tests in the subset of 64 exposed workers in 1990 and 1992 (liver test results not shown).

Table 2 summarises the results of the renal tests of the exposed and both control groups of the present occupational health assessment. There were no significant differences between the exposed workers and the refinery workers (control 1), but albumin was significantly 
Table 2 Median (range) results of the renal function tests in the exposed and control groups

\begin{tabular}{|c|c|c|c|}
\hline & \multicolumn{2}{|l|}{ Shift workers } & \multirow{2}{*}{$\begin{array}{l}\text { Day workers } \\
\text { Control } 2\end{array}$} \\
\hline & Exposed & Control 1 & \\
\hline \multirow[t]{2}{*}{$\begin{array}{l}\text { Alanine aminopeptidase (U/g creatinine) } \\
\text { Albumin (mg/g creatinine) } \\
\beta_{2} \text {-Microglobulin }(\mu \mathrm{g} / \mathrm{g} \text { creatinine) } \\
\text { Serum creatinine }(\mu \mathrm{M}) \\
N \text {-acetyl- } \beta \text {-D-glucosaminidase } \\
\text { (U/g creatinine) }\end{array}$} & $\begin{array}{c}4 \cdot 4(2 \cdot 1-9 \cdot 3) \\
5 \cdot 8^{\star}(2 \cdot 0-117) \\
59(13-375) \\
93(75-127)\end{array}$ & $\begin{array}{l}4 \cdot 4(2 \cdot 2-9 \cdot 2) \\
5 \cdot 7 \dagger(2 \cdot 5-215) \\
57 \cdot 5(14-306) \\
94(72-122)\end{array}$ & $\begin{array}{l}4 \cdot 4(2 \cdot 2-7 \cdot 7) \\
4 \cdot 7^{\star} \dagger(2 \cdot 1-113) \\
64 \cdot 5(15-446) \\
92(75-118)\end{array}$ \\
\hline & $1.03(0 \cdot 1-3 \cdot 7)$ & $1 \cdot 18(0 \cdot 3-2 \cdot 7)$ & $1 \cdot 24(0 \cdot 2-3 \cdot 1)$ \\
\hline
\end{tabular}

${ }^{\star}+$ Values with the same superscript differ significantly

lower in the maintenance workers (control 2) than in the exposed workers $(P=0.037)$ and the refinery workers $(P=0.013)$. There were no significant changes over the period from 1990 to 1992 in the results of the renal tests, except for alanine aminopeptidase, in the subset of 64 exposed workers who attended the health assessment in both years. The significantly higher value that was measured in 1992 compared with $1990(\mathrm{P}<0.001)$ was fully explained by the change in method.

\section{Discussion}

Table 1 shows that the exposed group matched well with both control groups for lifestyle and demographic factors. Except for the number of medication users, which was significantly higher in the refinery workers, the two control groups also matched well for these factors. Neither type nor frequency of medication was judged by the medical officer to affect the liver or the kidneys and it seemed that medication was not a significant confounder for any of the tests used. With the exception of the increase in age, no significant changes in lifestyle or demographic factors were found over the period 1990-1992 in the 64 potentially exposed workers who participated in both the occupational health assessments of 1990 and 1992. The three renal variables tested in both assessments give no indication of biochemical alterations in the period 1990-1992 as the only significant change (the increase in alanine aminopeptidase) was fully explained by a change in method.

In our previous study, in which the exposed workers were compared with a matched control group of office workers, significantly higher urinary albumin concentrations were found in the exposed group. ${ }^{1}$ All other variables gave no indications of any biochemical alterations in the liver or kidneys. In the present study, two years later, again no differences in liver function were found between the exposed workers and either of the two control groups. Also, there was no difference in any of the five renal variables tested between the group of exposed workers and the control group of refinery workers who work in five shifts (control group 1). A significantly higher urinary albumin concentration was found in the exposed group compared with the control group of maintenance workers who work only during day time (control group 2) whereas the other four renal variables did not differ. Comparing the results of the renal tests of the two control groups it seemed that only urinary albumin differed: it was significantly higher in control group 1 than in control group 2 . The difference in albumin between the groups of employees working in five shifts (exposed and control group 1) and those only working during day time (control group 2) is about the same as found in the previous study where the exposed workers were compared with a group of office employees, who also were only working during the day.

These results suggest that the higher albumin excretion found in the exposed workers may be due to the fact that they are employed on shift work rather than to the potential exposure to halogenated hydrocarbons. This would also explain the difference found in our previous study ${ }^{1}$ and the study in workers potentially exposed to aliphatic and aromatic hydrocarbons by Viau et $a l,{ }^{2}$ because in both studies potentially exposed shift workers were compared with office workers. This would also explain why in both of these studies the extent of albuminuria did not correlate with exposure levels, duration of exposure, or job titles.

It is known that an increase in urinary albumin excretion may be found after protein rich meals and following intense physical exercise. There are no reasons to suppose that there are major dietary differences between the exposed and control groups in any of the studies already mentioned, but a difference in overall physical activity would have been a possible explanation for the differences found in our previous study and the study by Viau et al as in both studies operators were compared with office workers whose jobs are most probably physically less demanding. In the present study two control groups were selected with job titles that demand about the same amount of physical activity as the jobs in the exposed group. From the results it is obvious that the difference in urinary albumin is not explained by differences in physical workload. It is also known that protein and in particular albumin excretion is subject to changes in renal haemodynamics, ${ }^{5}$ and it has been suggested that circadian variations may occur ${ }^{6}{ }^{7}$ irrespective of physical activity or posture ${ }^{8}$ In rats a distinct circadian rhythm was found for albumin excretion, which was disturbed by stress and resulted in increased albuminuria. ${ }^{9}$ Although the exact mechanism of the increase in albumin excretion remains to be elucidated, we suggest that the slight increase in albuminuria in shift workers compared with workers employed in day duty only is due to alterations in circadian rhythms due to the shift system and is not a result of prolonged exposure to low concentrations of potentially nephrotoxic compounds.

1 Boogaard PJ, Rocchi PSJ, Van Sittert NJ. Effects of exposure to low concentrations of chlorinated hydrocarbon on the kidney and liver of industrial workers. $\mathrm{Br} \mathcal{F}$ Ind Med 1993;50:331-9.

2 Viau C, Bernard A, Lauwerys R, et al. A cross-sectional survey of kidney function in refinery employees. $A m \mathcal{F}$ Ind Med 1987;11:177-87.

3 Bernard AM, Moreau D, Lauwerys RR. Comparison of 
retinol-binding protein and $\beta_{2}$-microglobulin determination in urine for the early detection of tubular proteinuria. Clin Chim Acta 1982;126:1-7.

4 Mattenheimer H, Frölke W, Grötsch H, Maruhn D, Simane Z. Recommendation for the measurement of "imane Z. Recommendation for the measurement of "alanine aminopeptidase" in urine. Fournal of Clin

5 Bernard A, Lauwerys RR. Proteinuria: changes and mechanisms in toxic nephropathies. Crit Rev Toxicol 1991;21: 373-405.

6 Watts GF, Morris RW, Khan K, Polak A. Urinary albumin excretion in healthy adult subjects: reference values and some factors affecting their interpretation. Clin Chim
Acta 1988;172:191-8.

7 Capani F, D'Emilio A, Marchioli R, et al. Circadian rhythm of albumin excretion rate in healthy subjects. Chronobiologia 1988;15:213-6.

8 Buzio C, Arisi L, Capani F, Barani R, Quaretti P. Circadian rhythm of proteinuria in normal subjects but not in patients with glomerulonephritis. Ann Clin Res not in patients

9 Bergamaschi E, Mutti A, Alinovi R, et al. Circadian rhythm of proteinuria in rats. In: Bach PH, Gregg NJ, Wilks MF, Delacruz, eds. Nephrotoxicity: mechanisms, early diagnosis, and therapeutic management. New York: Marcel Dekker, 1991;76:495-500.

\section{Correspondence and editorials}

Occupational and Environmental Medicine welcomes correspondence relating to any of the material appearing in the journal. Results from preliminary or small scale studies may also be published in the correspondence column if this seems appropriate. Letters should be not more than 500 words in length and contain a minimum of references. Tables and figures should be kept to an absolute minimum. Letters are accepted on the understanding that they may be subject to editorial revision and shortening.

The journal also publishes editorials which are normally specially commissioned. The Editor welcomes suggestions regarding suitable topics; those wishing to submit an editorial, however, should do so only after discussion with the Editor. 